\title{
A new kid on the block
}

In 2012 the USA had more than 81,000 of them - the UK about 150 . We refer to physician assistants, now redesignated physician associates (PAs): 'a new healthcare professional who, while not a doctor, works to the medical model, with the attitudes, skills and knowledge base to deliver holistic care and treatment within the general medical and/or general practice team under defined levels of supervision'. ${ }^{1}$ In March this year, the Council of the Royal College of Physicians (RCP) approved the creation of a faculty of physician associates within the RCP.

Clinical Medicine has argued the case for PAs on a number of occasions. ${ }^{2,3}$ In 2012 Ross et al summarised the training of UK PAs - a 2-year postgraduate diploma with training split equally between theory and clinical practice - and highlighted the wide range of activities that the holders of the diploma were carrying out in UK hospitals, from cardiology to orthopaedics, from mental health to paediatric intensive care. ${ }^{4}$ They pointed out the benefits that PAs could bring to clinical teams, providing continuity, potentially over years, in contrast to the many junior medical staff who will rotate through a unit over the same time period. Furthermore, PAs have the versatility both to develop a specialised 'niche' within a clinical team and to provide a patient-focused medical perspective within highly specialised teams. Importantly for the latter, current agreements on re-certification of PAs, following the pattern established in the USA, involve an examination covering a wide curriculum of general medical knowledge, rather than just the specialised area in which an individual PA is employed. ${ }^{5}$ More recent articles have assessed the response of medical teams to the introduction of PAs both within a single setting and by nationwide survey. ${ }^{6,7}$ Generally these demonstrated very positive responses from supervising doctors and colleagues, with one describing them as 'an indispensable part of the team'. ${ }^{5}$

A particular niche for PAs will surely lie in emergency medicine. The specialty is experiencing substantial difficulty in recruiting trainees for higher training, with 'attrition' occurring most notably as doctors completing their ST3 years decide not to progress to ST4 training in the specialty. The Department of Health (DH)'s Emergency Medicine Taskforce recommended to Health Education England
(HEE) that the role of PAs should be better defined and the training opportunities expanded. In December 2013 HEE confirmed it was undertaking work with physician associate organisations, saying that it 'agrees that this professional group are ideally training to support emergency medicine. However it is recognised that until there is mandatory regulation, it is unlikely that there will be sufficient academic institutions establishing a programme'. ${ }^{8}$

Clinical Medicine highlighted the issue of statutory regulation last year, ${ }^{3}$ against a background of an apparent unwillingness of the $\mathrm{DH}$ to proceed along this path. The lack of statutory regulation brings with it clear limitations to the fulfilment of the role that PAs could reasonably be expected to play, most notably by bringing with it an inability to prescribe, and also providing a barrier to ordering radiological examinations. These two issues emerged as the major concerns of the PA supervisors surveyed by Williams and Ritsema. ${ }^{7}$

It would seem almost axiomatic that if the DH and HEE are urging expansion and better definition of the role of PAs the profession should be registered and regulated. This would be in the best interests of the service and of the public, who would come to recognise and respect the nature of the healthcare professional they may be seeing. Registration by the Health Care Professions Council, and indeed legal protection of the physician assistant title, would readily build on the voluntary register already maintained and subscribed to by the majority of PAs practising in the UK. ${ }^{9}$ It would protect the public from alternative, potentially less stringent, models of PA training, which currently could be set up. As a registered profession the case for PAs prescribing and ordering diagnostic radiology could be pushed forward; both of these would enhance the contribution that PAs could make to the care of patients in the hospital service.

Thus the establishment of a new faculty within the RCP offers a welcome path to progress the call by the Future Hospital Commission to develop the role of the PA, and to obtain statutory relation status for the profession, allowing it to make a more effective contribution to the health service and the health economy. ${ }^{10}$
Members of the editorial board

$\begin{array}{ll}\text { Professor Humphrey Hodgson } & \text { Dr Cordelia Coltart } \\ \text { Editor } & \text { International editor } \\ \text { Dr Paul Grant } & \text { Cono Ariti } \\ \text { Editorial registrar } & \text { Statistical editor }\end{array}$

Dr Na'eem Ahmed

Paul Belcher

Dr Rodger Charlton

Dr Tahseen Chowdhury

Dr Kate Evans

Professor Brian Hurwitz
Dr Angela King Professor Martin McKee

Dr Roby Rakhit

Dr Ian Starke

Dr Kevin Stewart 


\section{References}

1 Department of Health. The competence and curriculum framework for the physician assistant. London: DH, 2006. http://webarchive.nationalarchives.gov.uk/20130107105354/ http://www.dh.gov.uk/en/Publicationsandstatistics/Publications/ PublicationsPolicyAndGuidance/DH_4139317 [Accessed 25 March 2014].

2 Armitage M, Shepherd S. A new professional in the healthcare workforce: role, training, assessment and regulation. Clin $\mathrm{Med}$ 2005;5:311-4

3 Hodgson H. Physician assistants revisited. Clin Med 2013;13:3-4.

4 Ross N, Parle J, Begg P, Kuhns D. The case for the physician assistant. Clin Med 2012;12:200-6.

5 UK \& Ireland Universities Board for Physician Assistant Education, 2014. www.ukiubpae.sgul.ac.uk [Accessed 25 March 2014].
6 White $\mathrm{H}$, Round JE. Introducing physician assistants into an intensive care unit: process, problems, impact and recommendations. Clin Med 2013;13:15-18.

7 Williams LE, Ritsema TS. Satisfaction of doctors with the role of physician associates. Clin Med 2014;14:113-16.

8 Health Education England. Emergency Medicine: Background to HEE proposals to address workforce shortages. London: HEE, 2013. http://hee.nhs.uk/wp-content/uploads/sites/321/2013/12/ EM-publication-Nov131.pdf [Accessed 25 March 2014].

9 Physician Assistant Managed Voluntary Register, 2013. www.paregister. sgul.ac.uk [Accessed 25 March 2014].

10 Future Hospital Commission. Future hospital: caring for medical patients. A report from the Future Hospital Commission to the Royal College of Physicians. London: RCP, 2013. www.rcplondon.ac.uk/sites/default/ files/future-hospital-commission-report.pdf [Accessed 25 March 2014].

Humphrey Hodgson

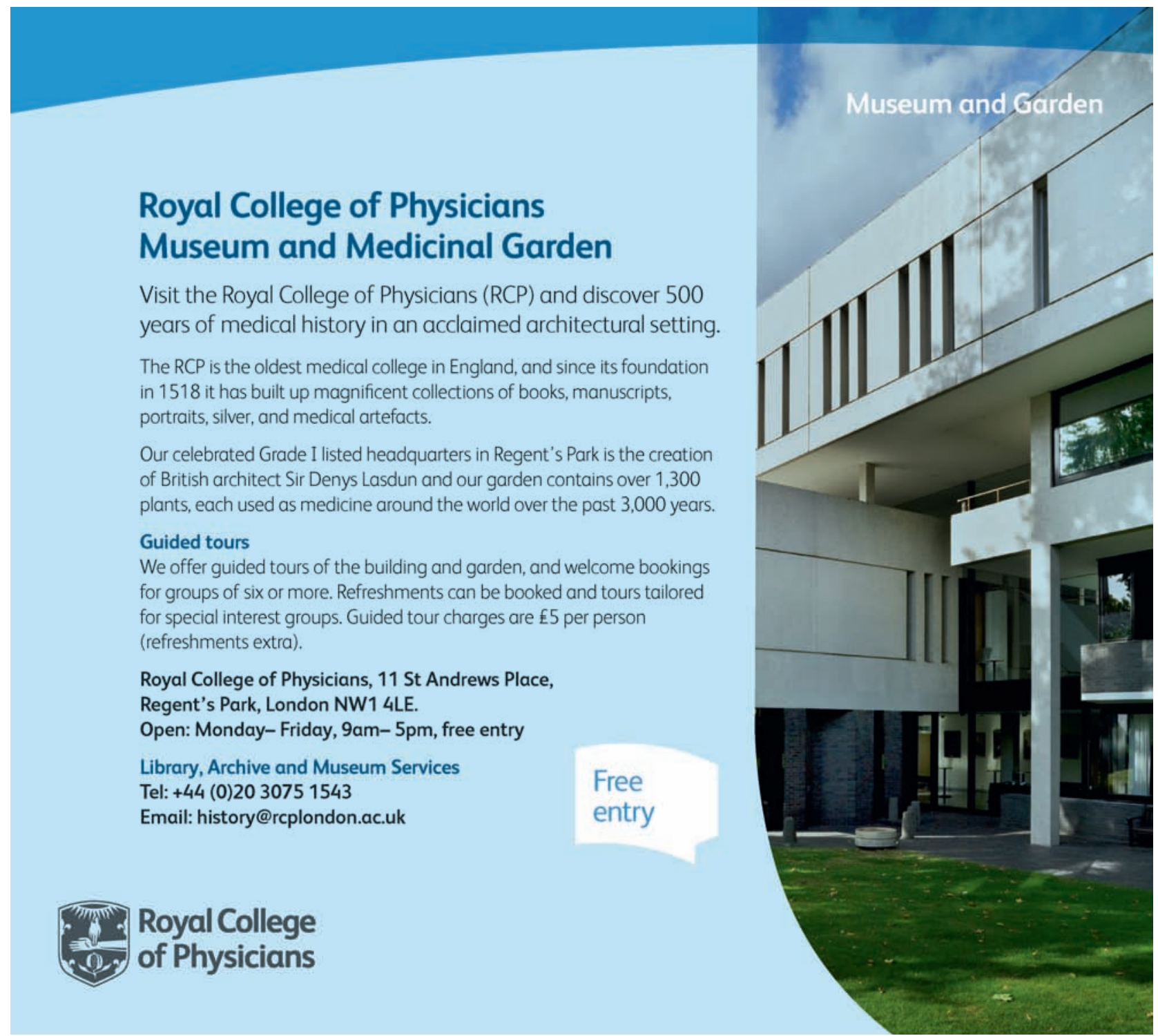

